\title{
Gastrointestinal complications are associated with a poor outcome in non-critically ill pneumonia patients
}

\author{
Chun-Ta Huang ${ }^{1,2^{*}} \mathbb{D}$, Chun-Ming Hong ${ }^{1}$, Yi-Ju Tsai ${ }^{3}$, Wang-Huei Sheng ${ }^{1}$ and Chong-Jen Yu ${ }^{1}$
}

\begin{abstract}
Background: Development of gastrointestinal (Gl) complications is adversely associated with prognosis in the critically ill. However, little is known about their impact on the outcome of non-critically ill patients. In this study, we aimed to investigate the incidence of $\mathrm{Gl}$ complications and their influence on prognosis of hospitalized pneumonia patients.
\end{abstract}

Methods: Adult patients admitted with a diagnosis of pneumonia from 2012 to 2014 were included. Medical records were reviewed to obtain patients' demographics, physical signs, comorbidities, laboratory results, clinical events, and the Confusion, Urea, Respiratory rate, Blood pressure and age $\geq 65$ (CURB-65) score was calculated to assess the severity of pneumonia. Gl complications, including bowel distension, diarrhea, Gl bleeding and ileus, were evaluated during the first 3 days of hospitalization and their association with patient outcomes, such as hospital mortality and length of stay, was analyzed.

Results: A total of 1001 patients were enrolled, with a mean age of 73.7 years and 598 (59\%) male. Among them, 114 (11\%) patients experienced at least one Gl complication and diarrhea (5.2\%) was the most common. The hospital mortality was $14 \%$ and was independently associated with an increase in the CURB-65 score (odds ratio [OR] 1.952 per point increase; 95\% confidence interval [Cl] 1.516-2.514), comorbid malignancy (OR 1.943; 95\% Cl 1.209-3.123), development of septic shock (OR 25.896; 95\% Cl 8.970-74.765), and the presence of any Gl complication (OR 1.753; 95\% Cl 1.003-3.065).

Conclusions: Compared to a critical care setting, Gl complications are not commonly observed in a non-critical care setting; however, they still have a negative impact on prognosis of pneumonia patients, including higher mortality and prolonged length of hospital stay.

Keywords: Complication, Gastroenterology, Pneumonia, Prognosis, Readmission

\section{Background}

The gastrointestinal (GI) tract is the largest organ system of the human body and exerts a variety of physiologic functions during a normal state. Other than serving as a digestive conduit, the GI tract also plays an important

\footnotetext{
*Correspondence: huangct@ntu.edu.tw

1 Department of Internal Medicine, National Taiwan University Hospital,

No. 7, Chung-Shan South Road, Taipei 100, Taiwan

Full list of author information is available at the end of the article
}

role in immunomodulation, hormone control, fluid and electrolyte balance, and physical protection from ingested environmental threats [1-3]. During the period of critical illness, GI complications may occur as a result of diverse injurious mechanisms, such as hypoperfusion, ischemia-reperfusion injury and pro-inflammatory cytokine responses $[1,4,5]$, and these complications are linked to increased mortality and morbidity among patients suffering from them $[5,6]$. In this regard, occurrence of GI complications under a myriad of conditions 
may not be simply viewed as an innocent victim but can otherwise precipitate deleterious consequences.

Along this line, GI dysfunction has been proposed to be the motor of multiple organ dysfunction in critical illness although the pathophysiology involved (e.g., bacterial translocation, altered intestinal tight junctions, cytokine production and interaction with the gut microbiome) remains incompletely understood [3, 7-9]. However, despite of scientific interest in this issue, the clinical relevance of GI complications is still controversial with an unknown yet probably adverse impact on the outcome of patients. In addition, outside of intensive care settings, little if any is known about the effects of GI complications on clinical trajectories and prognosis of non-critically ill patients.

Therefore, in this study, we aimed to investigate the incidence of GI complications and their influence on patient outcomes under a non-critical care setting. Specifically, we chose to focus on the analysis of clinical information on patients with pneumonia because it is the most common cause of hospitalization and carries a significant risk of mortality around the globe. Moreover, by this way, we could include a more homogeneous patient population for comparisons of clinical presentation and disease severity between different groups of study subjects.

\section{Materials and methods}

\section{Study settings and population}

This retrospective observational study was conducted at a university-affiliated hospital in Taiwan. The protocol has been approved by the Research Ethics Committee of the National Taiwan University Hospital (201902005RIND) and written informed consent was waived because of the retrospective and non-interventional design of the study.

Adult patients $\geq 20$ years of age admitted to the general medical wards between January 2012 and December 2014 were screened for eligibility in this study. Patients with an admission diagnosis of pneumonia were identified as the study subjects. The diagnosis of pneumonia was verified by a board-certified chest physician based on the overall medical records and radiologic findings [10]. For patients who were hospitalized twice or more during the study period, we included only the first hospitalization. Patients were excluded if they had an admission diagnosis other than pneumonia, were transferred from other facilities, or had missing data for calculating the severity score for pneumonia. In addition, patients with pre-existing GI disorders that may interfere the assessment of GI complications, such as inflammatory bowel disease, gastric/colorectal cancer, colostomy/ileostomy, and short bowel syndrome, were also excluded from the analysis.

\section{Data collection and definitions}

Data retrieved on hospital admission included patient demographics, physical signs, comorbidities, laboratory testing results, and pertinent clinical events. Comorbidities of interest were chronic kidney disease, chronic obstructive pulmonary disease, coronary artery disease, diabetes mellitus, heart failure and malignancy $[11,12]$. The Confusion, Urea, Respiratory rate, Blood pressure and age $\geq 65$ (CURB-65) score was calculated to assess the severity of pneumonia [13]. GI complications were evaluated during the first 3 days of hospitalization and their definitions were described as follows: (a) bowel dilatation: radiologically confirmed bowel dilatation in any bowel segment; (b) diarrhea: loose or liquid stool three or more times per day; (c) GI bleeding: appearance of blood in vomited fluids, nasogastric aspirate or stool; (4) ileus: absence of stool for three or more days $[2,5]$. Pertinent clinical events included development of septic shock and acute respiratory distress syndrome $[14,15]$, which were also assessed in the first 3 hospital days. In case that patients were rehospitalized after the index admission, the main reasons for rehospitalization were also obtained and categorized as infectious or non-infectious etiologies.

\section{Outcomes}

Patients were followed up until death, 30 days after discharge or loss to follow-up, whichever came first. The primary outcome was the survival status at hospital discharge. Other outcomes of interest included length of stay during the hospitalization, and incidence of unscheduled readmission and time to readmission within 30 days after the index discharge among the hospital survivors.

\section{Statistical analysis}

Continuous variables were presented as mean \pm standard deviation or median (interquartile range) per data distribution, and were analyzed by the independent sample $t$-test or Mann-Whitney test, respectively. Categorical variables were reported as number (\%) and were compared using the chi-square or Fisher's exact test, as appropriate. The logistic regression model was built to identify factors independently associated with hospital mortality in the multivariate analysis. Variables of laboratory testing were dichotomized by either the upper or lower limit of the reference range, as appropriate. All potentially confounding covariates were entered into the multivariate model without model selection. A two-tailed $P$ value of $<0.05$ indicated statistical significance. The statistical analyses were conducted by using 
the SPSS version 15.0 (SPSS Inc., Chicago, IL) software package.

\section{Results}

During the study period, a total of 1001 patients were included in this study (Fig. 1). The mean age of the study population was $73.7 \pm 15.2$ years and $598(59 \%)$ of them were males (Table 1). On average, the CURB-65 score was $1.6 \pm 1.0$. The leading comorbidities were diabetes mellitus (28\%), malignancy (19\%) and chronic obstructive pulmonary disease $(12 \%)$. Only few patients developed septic shock $(2.3 \%)$ or acute respiratory distress syndrome $(0.7 \%)$ in the first 3 days of hospitalization. The median length of hospital stay was $8(5-12)$ days. The incidences of GI complications are presented in Table 2. Diarrhea (5.2\%) was the most common complication and approximately 1 out of 9 patients (11\%) experienced one or more GI complications.

There were $862(86 \%)$ survivors and 139 (14\%) nonsurvivors on hospital discharge (Table 1). The non-survivors were older (77.2 vs. 73.2 years; $P=0.003$ ) and had a higher CURB-65 score (2.1 vs. $1.6 ; P<0.001)$ than the survivors. Also, non-survivors were more likely to have comorbid malignancy ( $28 \%$ vs. $17 \% ; P=0.002)$ and experience septic shock ( $12 \%$ vs. $0.7 \% ; P<0.001)$ compared to survivors. Regarding laboratory testing, a higher white blood cell count ( 13.0 vs. $11.0 \mathrm{~K} / \mu \mathrm{L} ; P=0.006)$, neutrophil-to-lymphocyte ratio (15.6 vs. $10.3 ; P<0.001)$, and

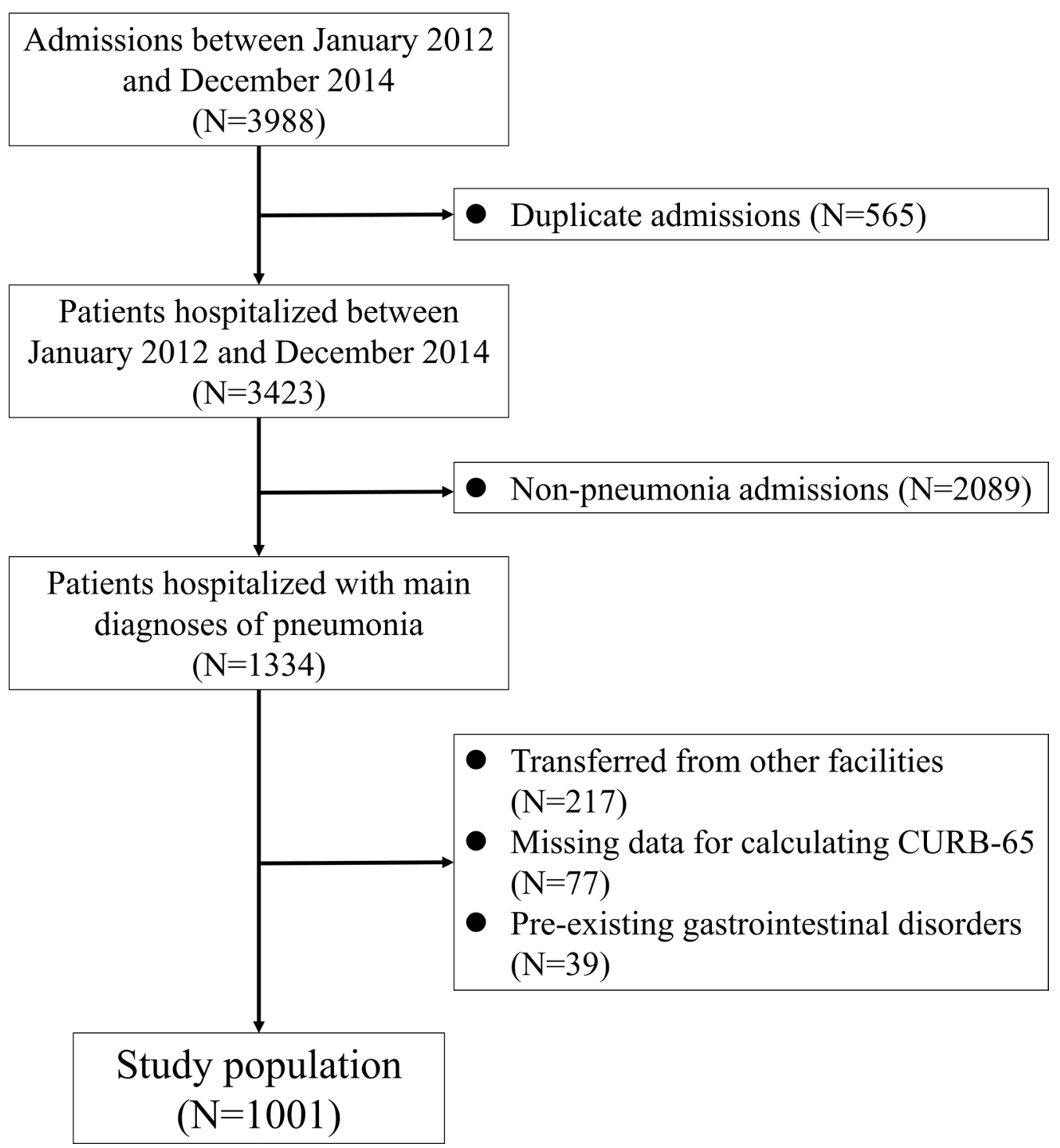

Fig. 1 Study flow diagram. CURB-65, Confusion, Urea, Respiratory rate, Blood pressure and age $\geq 65$ 
Table 1 Baseline characteristics of the study population

\begin{tabular}{|c|c|c|c|}
\hline \multirow[t]{2}{*}{ Characteristic } & \multirow{2}{*}{$\begin{array}{l}\text { Hospital survivors } \\
\mathrm{N}=862\end{array}$} & \multirow{2}{*}{$\begin{array}{l}\text { Hospital } \\
\text { non- } \\
\text { survivors } \\
\mathrm{N}=139\end{array}$} & \multirow[t]{2}{*}{$P$ value } \\
\hline & & & \\
\hline Age, years & $73.2 \pm 15.2$ & $77.2 \pm 14.7$ & 0.003 \\
\hline Male sex & $520(60)$ & $78(56)$ & 0.348 \\
\hline CURB-65 score & $1.6 \pm 1.0$ & $2.1 \pm 1.0$ & $<0.001$ \\
\hline 0 & $133(15)$ & $11(7.9)$ & $<0.001$ \\
\hline 1 & $259(30)$ & $27(19)$ & \\
\hline 2 & $322(37)$ & $51(37)$ & \\
\hline 3 & $138(16)$ & $40(29)$ & \\
\hline 4 & $10(1.2)$ & $10(7.2)$ & \\
\hline \multicolumn{4}{|l|}{ Comorbidity } \\
\hline Diabetes mellitus & $249(29)$ & $31(22)$ & 0.109 \\
\hline Malignancy & $148(17)$ & $39(28)$ & 0.002 \\
\hline COPD & $105(12)$ & $13(9.4)$ & 0.337 \\
\hline Coronary artery disease & $99(12)$ & $16(12)$ & 0.993 \\
\hline Heart failure & $84(9.7)$ & $15(11)$ & 0.701 \\
\hline Chronic kidney disease & $56(6.5)$ & $10(7.2)$ & 0.758 \\
\hline \multicolumn{4}{|l|}{ Laboratory testing } \\
\hline White blood cells, $\mathrm{K} / \mu \mathrm{L}$ & $11.0 \pm 6.1$ & $13.0 \pm 8.2$ & 0.006 \\
\hline $\begin{array}{l}\text { Neutrophil-to-lympho- } \\
\text { cyte ratio }\end{array}$ & $10.3 \pm 10.6$ & $15.6 \pm 12.8$ & $<0.001$ \\
\hline Albumin, g/dL & $3.4 \pm 0.3$ & $3.2 \pm 0.5$ & $<0.001$ \\
\hline $\begin{array}{l}\text { C-reactive protein, mg/ } \\
\text { dL }\end{array}$ & $7.4 \pm 4.8$ & $8.6 \pm 5.2$ & 0.017 \\
\hline \multicolumn{4}{|l|}{$\begin{array}{l}\text { Events in the first } 3 \text { hospi- } \\
\text { tal days }\end{array}$} \\
\hline Septic shock & $6(0.7)$ & $17(12)$ & $<0.001$ \\
\hline ARDS & $6(0.7)$ & $1(0.7)$ & 0.999 \\
\hline Length of stay, days & $8(6-12)$ & $8(3-14)$ & 0.025 \\
\hline
\end{tabular}

ARDS, acute respiratory distress syndrome; COPD, chronic obstructive pulmonary disease; CURB, Confusion, Urea, Respiratory rate, Blood pressure

Table 2 Incidence of gastrointestinal (GI) complications within 3 days of hospital admission between survivors and non-survivors

\begin{tabular}{|c|c|c|c|c|}
\hline Characteristic & $\begin{array}{l}\text { All } \\
N=1001\end{array}$ & $\begin{array}{l}\text { Survivors } \\
\mathrm{N}=862\end{array}$ & $\begin{array}{l}\text { Non-survivors } \\
\mathrm{N}=139\end{array}$ & $P$ value \\
\hline Diarrhea & $52(5.2)$ & $42(4.9)$ & $10(7.2)$ & 0.252 \\
\hline Bowel dilatation & $34(3.4)$ & $26(3.0)$ & $8(5.8)$ & 0.124 \\
\hline Ileus & $25(2.5)$ & $19(2.2)$ & $6(4.3)$ & 0.143 \\
\hline Gl bleeding & $14(1.4)$ & $10(1.2)$ & $4(2.9)$ & 0.117 \\
\hline Any Gl complication & $114(11)$ & $90(10)$ & $24(17)$ & 0.019 \\
\hline
\end{tabular}

C-reactive protein value $(8.6$ vs. $7.4 \mathrm{mg} / \mathrm{dL} ; P=0.017)$ were observed in non-survivors than survivors. On the contrary, non-survivors had lower serum albumin levels than survivors ( 3.2 vs. $3.4 \mathrm{~g} / \mathrm{dL} ; P<0.001)$. The length of hospital stay was longer in non-survivors compared to survivors ( 8 vs. 8 days in medians; $P=0.025$ ). Regarding GI complications, no statistically significant differences were found in any single complication between the survivors and non-survivors (Table 2). However, non-survivors more often developed any of the GI complications compared to survivors ( $17 \%$ vs. $10 \% ; P=0.019)$.

Table 3 shows the logistic regression model incorporating patient demographics, comorbidities, laboratory results, clinical events, CURB-65 scores and the presence of GI complications for odds ratios (ORs) of hospital mortality in the pneumonia patients. Independent risk factors of mortality included an increase in CURB65 scores (OR 1.952 per point increase; 95\% confidence interval [CI] 1.516-2.514), comorbid malignancy (OR 1.943; 95\% CI 1.209-3.123), development of septic shock (OR 25.896; 95\% CI 8.970-74.765), and the presence of any GI complication (OR 1.753; 95\% CI 1.003-3.065).

In addition to an association with increased hospital mortality, the presence of GI complications in patients with pneumonia was also associated with a longer hospital stay (Table 4). Moreover, among the pneumonia patients surviving to hospital discharge, those with any of the GI complications during the first 3 days of hospitalization seemed more likely to be readmitted within

\begin{tabular}{|c|c|c|c|}
\hline Parameter & Odds ratio & $95 \% \mathrm{Cl}$ & $P$ value \\
\hline Age, $\geq 65$ years & 2.189 & $1.169-4.097$ & 0.014 \\
\hline Male sex & 0.677 & $0.451-1.017$ & 0.060 \\
\hline CURB-65, per point increase & 1.952 & $1.516-2.514$ & $<0.001$ \\
\hline \multicolumn{4}{|l|}{ Comorbidity } \\
\hline Diabetes mellitus & 0.699 & $0.441-1.111$ & 0.130 \\
\hline Malignancy & 1.943 & $1.209-3.123$ & 0.006 \\
\hline Heart failure & 0.869 & $0.441-1.714$ & 0.686 \\
\hline Coronary artery disease & 1.028 & $0545-1.939$ & 0.933 \\
\hline Chronic kidney disease & 0.751 & $0.336-1.679$ & 0.486 \\
\hline COPD & 0.763 & $0.384-1.513$ & 0.438 \\
\hline \multicolumn{4}{|l|}{ Laboratory testing } \\
\hline White blood cells, $>9 \mathrm{~K} / \mu \mathrm{L}$ & 1.760 & $1.148-2.697$ & 0.010 \\
\hline $\begin{array}{l}\text { Neutrophil-to-lymphocyte } \\
\text { ratio, }>3\end{array}$ & 2.445 & $1.016-5.883$ & 0.046 \\
\hline Albumin, $<3.5 \mathrm{~g} / \mathrm{dL}$ & 2.421 & $1.554-3.771$ & $<0.001$ \\
\hline C-reactive protein, $\geq 0.8 \mathrm{mg} / \mathrm{dL}$ & 1.692 & $0.487-5.873$ & 0.407 \\
\hline \multicolumn{4}{|l|}{ Events in the first 3 hospital days } \\
\hline Septic shock & 25.896 & $8.970-74.765$ & $<0.001$ \\
\hline ARDS & 0.760 & $0.083-6.954$ & 0.808 \\
\hline Any Gl complication & 1.753 & $1.003-3.065$ & 0.048 \\
\hline
\end{tabular}

ARDS, acute respiratory distress syndrome; $\mathrm{Cl}$, confidence interval; COPD, chronic obstructive pulmonary disease; CURB, Confusion, Urea, Respiratory rate, Blood pressure; $\mathrm{Gl}$, gastrointestinal 


\begin{tabular}{llll}
$\begin{array}{l}\text { Table } 4 \text { Outcomes } \\
\text { of gastrointestinal (GI) complications }\end{array}$ & $\begin{array}{c}\text { regards } \\
\text { to the }\end{array}$ & presence \\
\hline Characteristic & $\begin{array}{l}\text { Without GI } \\
\text { complications }\end{array}$ & $\begin{array}{l}\text { With Gl } \\
\text { complications }\end{array}$ & P value \\
\hline $\begin{array}{l}\text { During hospitalization } \\
\text { Number of patients }\end{array}$ & $\mathrm{N}=887$ & $\mathrm{~N}=114$ & \\
$\begin{array}{l}\text { Length of stay, days } \\
\text { Hospital mortality }\end{array}$ & $8(5-12)$ & $10(6-14)$ & 0.038 \\
$\begin{array}{l}\text { Post-discharge } \\
\text { Number of patients }\end{array}$ & $\mathrm{N}=666$ & $\mathrm{~N}=80$ & \\
Readmission & $96(14)$ & $18(23)$ & 0.019 \\
Infectious & $76(11)$ & $12(15)$ & \\
$\quad$ Non-infectious & $20(3.0)$ & $6(7.5)$ & \\
Time to readmission, days & $14.3 \pm 7.9$ & $13.0 \pm 8.5$ & 0.537 \\
\hline
\end{tabular}

a Follow-up status was available in 746 patients

30 days of discharge than those without, and the majority $(77 \%)$ of all these readmissions were ascribed to infectious diseases.

\section{Discussion}

The present study shows that, in a non-critical care setting, 1 out of 9 pneumonia patients would experience GI complications during the first 3 days of admission and these complications were associated with a higher odds of hospital mortality and a longer length of hospital stay. In addition, among the hospital survivors, those with GI complications were more likely to be rehospitalized within 30 days of the index discharge. Taken together, the findings indicate a deleterious role of GI complications in patients hospitalized for pneumonia and suggest that the importance of the GI tract in the pathophysiology of non-GI diseases should not be overlooked.

Several observational studies on critically ill patients consistently show an adverse impact of GI complications on the risk of mortality although the definitions of complications and their observation windows significantly differ between studies [5, 16-19]. Reintam-Blaser et al. reported that GI failure, defined as the presence of food intolerance, GI bleeding or ileus, was related to significantly higher mortality as well as prolonged lengths of intensive care unit (ICU) stay and mechanical ventilation [17]. The same study group later proposed a GI failure score, combining food intolerance and intra-abdominal hypertension into a 5-grade scoring system, and identified the GI failure score in the first 3 ICU days as an independent risk factor for ICU mortality [18]. They also demonstrated that during the first week of ICU admission, certain specific GI complications, including absent bowel sounds, GI bleeding and bowel distension, and the total number of GI complications were associated with 28-day mortality [5]. To the best of our knowledge, the current study is the first one to evaluate the prognostic role of GI complications in a less severe patient population. In line with the findings from ICU studies, development of GI complications in hospitalized pneumonia patients was associated with poor clinical outcomes, including hospital mortality and length of stay. In summary, our findings emphasize the importance of GI complications and extend their role from the critical to non-critical care settings.

Compared to ICU studies $[5,20,21]$, the incidence of global GI complications in our study was quite low $(59-80 \%$ vs. $11 \%)$. This may simply reflect the association between the severity of acute illness and risks of GI complications, as shown in two prospective observational studies [20,22]. Zhang et al. showed a strong positive correlation between acute GI injury grading system and the acute physiology and chronic health evaluation (APACHE) II score [22]. Reintam-Blaser et al. found that the sequential organ failure assessment (SOFA) score on ICU admission was predictive of the development of GI symptoms [20]. In terms of individual GI complications, diarrhea, ileus, bowel distension and GI bleeding are commonly described in the literature [2], with a wide range of reported incidences (e.g., from 2 to $95 \%$ for diarrhea in the critically ill) [23]. Some of those complications, such as GI bleeding and bowel distension, have been reportedly associated with ICU or 28-day mortality $[5,24]$. However, none of the GI complications alone was found to be predictive of hospital mortality in the current study, although the incidence of each complication was unanimously higher in non-survivors than in survivors (Table 2). Our study, probably limited by the study design and settings, may be underpowered to detect such a small, if any, effect size.

A major obstacle to studying GI complications is that the definitions are often varied, vague and elusive. The terminology can also be confusing. Terms, such as acute GI injury, food intolerance and GI failure, have been used interchangeably or to indicate different GI conditions across the literature [25]. Moreover, lack of objective measures of GI functions and validated biomarkers add to the complexity in this area [26]. In this regard, the Working Group on Abdominal Problems of the European Society of Intensive Care Medicine presented a consensus statement on the definitions and grading system of GI dysfunction for ICU patients [2]. Other investigators have provided evidence to support the prognostic significance of the acute GI injury grading system in the critically ill patients $[19,22]$. In our study, however, this grading system was not utilized since high-grade GI injury was expected to occur sparsely among pneumonia patients admitted to 
general wards. Instead, simple, easily recognizable GI signs and symptoms were used to delineate the clinical profile of GI complications in our study population. As the first study in this field, our results should encourage researches to define explicit characteristics of GI conditions in non-critically ill patients.

An interesting finding in this study is that pneumonia patients with GI complications were readmitted within 30 days of discharge more often than those without, although the difference did not reach statistical significance. Great efforts have been put on identification of risk factors for readmission following hospitalization for pneumonia. Comorbidities, socioeconomic status, and so on play a pivotal role in this regard [27, 28]; however, to our knowledge, none of the studies identified the association between GI dysfunction during the index hospitalization and risks of readmission. Our finding may not be that unexpected but is pathophysiologically plausible. Gut origin of sepsis hypothesis proposes that translocation of potentially harmful bacteria across the intestinal barrier causes sepsis at distant sites [29]. Thus, GI dysfunction may render the host susceptible to infections and consequently result in rehospitalization. The observation that the majority of readmissions in this study could be ascribed to infectious diseases may partly support this hypothesis.

A number of limitations pertaining to this study should be considered. First, the incidence of GI complications can be underestimated since clinically insignificant events may not be reported by the patients or well documented in the medical records. However, important and influential GI conditions are unlikely to be missed, and our results are practically informative to clinicians in daily practice. Second, that only pneumonia patients were enrolled for analysis may limit the generalizability of the study findings to other non-critically ill populations. Nonetheless, inclusion of this non-GI disease alone is also the strength of our study because we were able to clearly delineate and analyze the effects of GI complications on patient outcomes. Undoubtedly, more studies are encouraged to validate our findings in other disease contexts. Third, the impact of pre-existing GI disorders on GI complications and the interactions between them remain to be elucidated. In our study, patients with pre-morbid GI diseases were excluded from analysis in order to distinctly define the development of GI complications. This is the advantage and also the disadvantage of our study design, and prospective, well-defined studies (e.g., meaningful changes in GI signs and symptoms) are required to solve these issues.

\section{Conclusions}

GI complications are not that commonly observed outside of ICU settings; however, they still exert a negative impact on prognosis of pneumonia patients, including higher mortality and prolonged length of hospital stay. In addition, development of those complications in patients with pneumonia during the index hospitalization seems to be associated with the post-discharge outcome, namely, 30-day rehospitalization. Therefore, the findings altogether illustrate the important prognostic role of GI complications in patients with non-GI diseases under a non-critical care setting.

\section{Abbreviations \\ APACHE: Acute physiology and chronic health evaluation; Cl: Confidence inter- val; CURB-65: Confusion, Urea, Respiratory rate, Blood pressure and age $\geq 65$; GI: Gastrointestinal; ICU: Intensive care unit; OR: Odds ratio; SOFA: Sequential organ failure assessment.}

\section{Acknowledgements}

We thank the staff of the Eighth Core Lab, Department of Medical Research, National Taiwan University Hospital for technical support during the study. We also specially thank Drs. Yu-Feng Lin, Chin-Chung Shu, Nin-Chieh Hsu, Chia-Lin Tseng, Pao-Yu Chen, Hung-Bin Tsai, Yen-Lin Chen, Jia-Ling Yang, and Fan-Chi Chang for their contribution to taking care of the patients.

\section{Authors' contributions}

CTH: conceptualization; data curation; formal analysis; funding acquisition; project administration; writing — original draft. CMH: conceptualization; investigation; writing —original draft. YJT: formal analysis; investigation; project administration; writing — review and editing. WHS: investigation; supervision; writing —review and editing. CJY: investigation; supervision; writing—review and editing. All authors read and approved the final manuscript.

\section{Funding}

This study was supported by grants from the Ministry of Science and Technology (107-2314-B-002-238-MY3), Taipei, Taiwan and the National Taiwan University Hospital (NTUH.109-S4794), Taipei, Taiwan. The funding sources had no roles in study design; in the collection, analysis and interpretation of data; in the writing of the report; and in the decision to submit the article for publication.

\section{Availability of data and materials}

The datasets used and/or analyzed during the current study are available from the corresponding author on reasonable request.

\section{Ethics approval and consent to participate}

The protocol has been approved by the Research Ethics Committee of the National Taiwan University Hospital (201902005RIND) and written informed consent was waived because of the retrospective and non-interventional design of the study.

\section{Consent for publication}

Not applicable.

\section{Competing interests}

The authors declare that they have no competing interests.

\section{Author details}

1 Department of Internal Medicine, National Taiwan University Hospital, No. 7, Chung-Shan South Road, Taipei 100, Taiwan. ${ }^{2}$ Graduate Institute of Clinical Medicine, National Taiwan University, Taipei, Taiwan. ${ }^{3}$ Graduate Institute of Biomedical and Pharmaceutical Science, College of Medicine, Fu Jen Catholic University, New Taipei City, Taiwan. 
Received: 20 July 2020 Accepted: 10 November 2020

Published online: 16 November 2020

\section{References}

1. Vazquez-Sandoval A, Ghamande S, Surani S. Critically ill patients and gut motility: are we addressing it? World J Gastrointest Pharmacol Ther. 2017:8:174-9

2. Reintam Blaser A, Malbrain ML, Starkopf J, Fruhwald S, Jakob SM, De Waele J, et al. Gastrointestinal function in intensive care patients: terminology, definitions and management. Recommendations of the ESICM Working Group on Abdominal Problems. Intensive Care Med. 2012:38:384-94

3. Klingensmith NJ, Coopersmith CM. The Gut as the Motor of Multiple Organ Dysfunction in Critical Illness. Crit Care Clin. 2016;32:203-12.

4. de Jong PR, Gonzalez-Navajas JM, Jansen NJ. The digestive tract as the origin of systemic inflammation. Crit Care. 2016;20:279.

5. Reintam Blaser A, Poeze M, Malbrain ML, Bjorck M, Oudemans-van Straaten HM, Starkopf J, et al. Gastrointestinal symptoms during the first week of intensive care are associated with poor outcome: a prospective multicentre study. Intensive Care Med. 2013:39:899-909.

6. Mangi AA, Christison-Lagay ER, Torchiana DF, Warshaw AL, Berger DL. Gastrointestinal complications in patients undergoing heart operation: an analysis of 8709 consecutive cardiac surgical patients. Ann Surg. 2005;241:895-901 ((discussion-4)).

7. Sertaridou E, Papaioannou V, Kolios G, Pneumatikos I. Gut failure in critical care: old school versus new school. Ann Gastroenterol. 2015;28:309-22.

8. Clark JA, Coopersmith CM. Intestinal crosstalk: a new paradigm for understanding the gut as the "motor" of critical illness. Shock. 2007;28:384-93.

9. Alverdy JC, Laughlin RS, Wu L. Influence of the critically ill state on hostpathogen interactions within the intestine: gut-derived sepsis redefined. Crit Care Med. 2003;31:598-607.

10. Kalil AC, Metersky ML, Klompas M, Muscedere J, Sweeney DA, Palmer LB, et al. Executive summary: management of adults with hospital-acquired and ventilator-associated pneumonia: 2016 Clinical Practice Guidelines by the Infectious Diseases Society of America and the American Thoracic Society. Clin Infect Dis. 2016;63:575-82.

11. Kaukonen KM, Bailey M, Suzuki S, Pilcher D, Bellomo R. Mortality related to severe sepsis and septic shock among critically ill patients in Australia and New Zealand, 2000-2012. JAMA. 2014;311:1308-16.

12. Yang Y, Yang KS, Hsann YM, Lim V, Ong BC. The effect of comorbidity and age on hospital mortality and length of stay in patients with sepsis. J Crit Care. 2010;25:398-405.

13. Lim WS, van der Eerden MM, Laing R, Boersma WG, Karalus N, Town Gl, et al. Defining community acquired pneumonia severity on presentation to hospital: an international derivation and validation study. Thorax. 2003;58:377-82.

14. Singer M, Deutschman CS, Seymour CW, Shankar-Hari M, Annane D, Bauer $M$, et al. The Third International Consensus Definitions for Sepsis and Septic Shock (Sepsis-3). JAMA. 2016:315:801-10.

15. Force ADT, Ranieri VM, Rubenfeld GD, Thompson BT, Ferguson ND, Caldwell $\mathrm{E}$, et al. Acute respiratory distress syndrome: the Berlin definition. JAMA. 2012;307:2526-33.
16. Reintam Blaser A, Starkopf L, Deane AM, Poeze M, Starkopf J. Comparison of different definitions of feeding intolerance: a retrospective observational study. Clin Nutr. 2015;34:956-61.

17. Reintam A, Parm P, Redlich U, Tooding LM, Starkopf J, Kohler F, et al. Gastrointestinal failure in intensive care: a retrospective clinical study in three different intensive care units in Germany and Estonia. BMC Gastroenterol. 2006;6:19.

18. Reintam A, Parm P, Kitus R, Starkopf J, Kern H. Gastrointestinal failure score in critically ill patients: a prospective observational study. Crit Care. 2008;12:R90

19. Hu B, Sun R, Wu A, Ni Y, Liu J, Guo F, et al. Severity of acute gastrointestinal injury grade is a predictor of all-cause mortality in critically ill patients: a multicenter, prospective, observational study. Crit Care. 2017;21:188.

20. Reintam A, Parm P, Kitus R, Kern H, Starkopf J. Gastrointestinal symptoms in intensive care patients. Acta Anaesthesiol Scand. 2009;53:318-24.

21. Atasever AG, Ozcan PE, Kasali K, Abdullah T, Orhun G, Senturk E. The frequency, risk factors, and complications of gastrointestinal dysfunction during enteral nutrition in critically ill patients. Ther Clin Risk Manag. 2018;14:385-91.

22. Zhang D, Li N, Dong L, Fu Y, Liu Z, Wang Y. Evaluation of clinical application of ESICM acute gastrointestinal injury grading system: a singlecenter observational study. Chin Med J (Engl). 2014;127:1833-6.

23. Thibault R, Graf S, Clerc A, Delieuvin N, Heidegger CP, Pichard C. Diarrhoea in the ICU: respective contribution of feeding and antibiotics. Crit Care. 2013:17:R153.

24. Kumar S, Ramos C, Garcia-Carrasquillo RJ, Green PH, Lebwohl B. Incidence and risk factors for gastrointestinal bleeding among patients admitted to medical intensive care units. Frontline Gastroenterol. 2017;8:167-73.

25. McClave SA, Gualdoni J, Nagengast A, Marsano LS, Bandy K, Martindale RG. Gastrointestinal dysfunction and feeding intolerance in critical illness: do we need an objective scoring system? Curr Gastroenterol Rep. 2020;22:1.

26. Antonelli M, Azoulay E, Bonten M, Chastre J, Citerio G, Conti G, et al. Year in review in Intensive Care Medicine 2010: II. Pneumonia and infections, cardiovascular and haemodynamics, organization, education, haematology, nutrition, ethics and miscellanea. Intensive Care Med. 2011;37:196-213.

27. Jasti H, Mortensen EM, Obrosky DS, Kapoor WN, Fine MJ. Causes and risk factors for rehospitalization of patients hospitalized with communityacquired pneumonia. Clin Infect Dis. 2008;46:550-6.

28. Toledo D, Soldevila N, Torner N, Perez-Lozano MJ, Espejo E, Navarro G, et al. Factors associated with 30-day readmission after hospitalisation for community-acquired pneumonia in older patients: a cross-sectional study in seven Spanish regions. BMJ Open. 2018;8:e020243.

29. MacFie J. Surgical sepsis. Br J Surg. 2013;100:1119-22.

\section{Publisher's Note}

Springer Nature remains neutral with regard to jurisdictional claims in published maps and institutional affiliations.

Ready to submit your research? Choose BMC and benefit from

- fast, convenient online submission

- thorough peer review by experienced researchers in your field

- rapid publication on acceptance

- support for research data, including large and complex data types

- gold Open Access which fosters wider collaboration and increased citations

- maximum visibility for your research: over 100M website views per year

At BMC, research is always in progress.

Learn more biomedcentral.com/submissions 